\title{
Cloning, expression, and characterization of Fe-SOD from Isöetes sinensis
}

\author{
Y. Xu ${ }^{1}$, X.L. Dai ${ }^{1}$, B.D. Liu $^{2}$ and Q.X. Wang ${ }^{1}$ \\ 'Shanghai Normal University, Shanghai, China \\ ${ }^{2}$ Harbin Normal University, Harbin, China \\ Corresponding author: Q.X. Wang \\ E-mail: wangqx1233@163.com
}

Genet. Mol. Res. 15 (4): gmr15047131

Received July 2, 2015

Accepted August 9, 2016

Published November 3, 2016

DOI http://dx.doi.org/10.4238/gmr15047131

Copyright $(2016$ The Authors. This is an open-access article distributed under the terms of the Creative Commons Attribution ShareAlike (CC BY-SA) 4.0 License.

\begin{abstract}
Although the palynology and sporophyte stage of Isöetes sinensis have been well studied, the biology of its gametophyte and embryo is less well understood. To date, the functions of several genes of $I$. sinensis and the molecular mechanisms of enzymes encoded by them remain to be studied. In the present study, the $\mathrm{Fe}-S O D$ gene of $I$. sinensis was successfully cloned using RT-PCR and rapid amplification of cDNA ends (RACE), and termed IsFeSOD. IsFeSOD has certain reference value in the classification of system evolution. The study also accumulated data for further research on the SOD gene. Bioinformatic analysis was employed to compare $I S F e S O D$ with gene sequences obtained from other plants present in the GenBank. Furthermore, the recombinant pET32-FeSOD plasmids were transformed into Escherichia coli BL21 for expression. IsFeSOD was observed to have 1469 nucleotides that were predicted to encode 247 amino acids. The bioinformatic analysis revealed that $I_{S} F e S O D$ contained conserved TGGGA sequences, similar to eight other species, in addition to five other conserved sequences. The recombinant protein was about $43 \mathrm{kDa}$.
\end{abstract}

Genetics and Molecular Research 15 (4): gmr15047131 
Recombinant FeSOD was expressed, purified, and confirmed by western blotting. Alignment of complete $\mathrm{Fe}-\mathrm{SOD}$ mRNA sequences from 9 species revealed several conserved sequences. A phylogenetic tree was constructed using MEGA4.1 and ClustalX multiple-sequence alignment programs. This study could be helpful in further characterization of SOD genes and for classification of system evolution status.

Key words: Isöetes sinensis; Lycophytina; Fern; Fe-SOD; RACE

\section{INTRODUCTION}

Isöetes sinensis is one of the five species of Isöetes, the only surviving genus of the Isöetaceae family, in China (found in Taiwan). Isöetes is a cosmopolitan genus of 200 or more species, belonging to heterosporous lycopods (Hoot and Taylor, 2001; Chen et al., 2005). In China in recent years, the number of individuals in each Isöetes species has declined, and several populations have even gradually disappeared from many locations in Mainland China ( $\mathrm{Fu}, 1989$; Zhang, 1997). In China, this genus is now considered rare and threatened or endangered and is listed among the top category of key, protected, wild plants (Yu, 1999). According to Ching's system, I. sinensis belongs to Isöephytina (Ching, 1978). However, based on molecular data, some scholars suggest that $I$. sinensis should be classified into Lycophytina (Liu et al., 2008).

Under normal growth conditions, cells of aerobic organisms produce low amounts of reactive oxygen species (ROS) but metabolic processes enhance the production under biotic and abiotic stress and the increased ROS concentrations affect many cellular functions by damaging nucleic acids, oxidizing proteins, and causing lipid peroxidation (Polle, 2001). Plants have welldeveloped antioxidant systems, both enzymatic and non-enzymatic, that provide innate immunity against ROS (Alscher et al., 2002; Geret et al., 2004; Manduzio et al., 2004). Superoxide dismutases (SODs) constitute the first line of cellular defense against ROS; they rapidly convert superoxide $\left(\mathrm{O}^{2-}\right)$ to hydrogen peroxide $\left(\mathrm{H}_{2} \mathrm{O}_{2}\right)$, enzymatically (Bowler et al., 1992). Most plants contain several SOD isozymes. Based on their metal cofactors, SODs are classified into three groups: iron SOD (FeSOD), manganese SOD (MnSOD), and copper-zinc SOD (Cu/ZnSOD) (Scandalios, 1997). FeSOD is found in both prokaryotes and plants, but not animals and fungi. Several regions in the FeSOD sequences of plants and cyanobacteria are conserved but are absent in nonphotosynthetic bacteria, suggesting that the FeSOD gene originated in the plastid genome and relocated to the nuclear genome following endosymbiosis during evolution (Bowler et al., 1994).

In the present study, we report the cloning of FeSOD from I. sinensis. The results obtained might provide insights into the function of IsFeSOD, and also the relationship between ferns and Lycophytina. Furthermore, valuable data for the study of FeSOD gene evolution were also obtained.

\section{MATERIAL AND METHODS}

\section{Plant material}

I. sinensis, procured from the Harbin Normal University (Prof. Baodong Liu's Laboratory), was cultivated at the Shanghai Normal University for a few months and used for the experiments.

Genetics and Molecular Research 15 (4): gmr15047131 


\section{Total RNA isolation}

RNA was isolated from tissue (including leaves, megasporangium, microsporangium, and roots) pulverized under liquid nitrogen. Total RNA was extracted using an EASYspin kit (Yanpinghao, Tianjin, China) following the manufacturer's instructions. RNA used for RTPCR was treated with RQ1 RNase-free DNase I (Promega, Madison, WI, USA), to remove any possible DNA contamination. Complementary DNA was synthesized using the total RNA employing Superscript III reverse transcriptase (Life Technologies, USA) and oligo(dT) primer, under standard conditions. Water was used instead of reverse transcriptase in the negative control to detect any possible genomic DNA contamination of the RNA samples.

\section{RT-PCR}

Two degenerate primers P1: 5'-GARTTYCACTGGGGIAARCAYC-3' and P2: 5'-GTARGCRTGCTCCCARACRTC-3' (where R $=\mathrm{A}$ or $\mathrm{G}, \mathrm{I}=$ inosine, and $\mathrm{Y}=\mathrm{C}$ or $\mathrm{T}$ ) were designed for the SOD gene from I. sinensis. Touchdown PCR was performed using the following program: $5 \mathrm{~min}$ at $94^{\circ} \mathrm{C}(1 \mathrm{cycle})$, followed by $30 \mathrm{~s}$ at $94^{\circ} \mathrm{C}, 30 \mathrm{~s}$ at $60^{\circ} \mathrm{C}$, and $45 \mathrm{~s}$ at $72^{\circ} \mathrm{C}$ ( 35 cycles), and a final extension at $72^{\circ} \mathrm{C}$ for $10 \mathrm{~min}$. The PCR products were separated on $2 \%$ agarose gels.

To exclude errors in PCR, at least two clones obtained from independent PCRs were sequenced. When discrepancies were observed, the majority sequence from at least three independently amplified PCR products was considered correct.

\section{RACE (5'- and 3'-rapid amplification of cDNA ends)}

To extend the IsFeSOD sequence in the 5'- and 3'-directions, we performed RACE using an SMARTer ${ }^{\mathrm{TM}}$ RACE cDNA Amplification kit (Clontech, Japan), according to the manufacturer instructions. Amplifications of 5'- and 3'-ends were performed using touchdown PCR with the following primers: primer pair one (RACE 5'-Primer 1: 5'-TCAATAATAGCC AAGCCCATCC-3'; RACE 5'-Primer 2: 5'-ATTGGGTCCTTTACCACCTTCT-3') and primer pair two (RACE 3'-Primer 1: 5'-ATGAAGCCAGAAGGTGGTAAAGG-3'; RACE 3'-Primer 2: 5'-TGGTAAAGGACCCAATGGAGAAT-3'). The PCR mix contained 1/10th volume cDNA solution, $20 \mu \mathrm{M}$ of each primer, $2 \mathrm{mM}$ dNTPs, $25 \mathrm{mM} \mathrm{MgSO}_{4}$, 10X PCR buffer, and $1 \mathrm{U}$ KOD polymerase (Toyobo, Japan). The PCR conditions used for 5'-RACE PCR were as follows: 5 min at $94^{\circ} \mathrm{C}\left(1\right.$ cycle), followed by $30 \mathrm{~s}$ at $98^{\circ} \mathrm{C}, 30 \mathrm{~s}$ at $55^{\circ} \mathrm{C}$, and $30 \mathrm{~s}$ at $68^{\circ} \mathrm{C}(30 \mathrm{cycles})$, and a final extension at $68^{\circ} \mathrm{C}$ for $8 \mathrm{~min}$. For $3^{\prime}$-RACE PCR, the conditions were as follows: $5 \mathrm{~min}$ at $94^{\circ} \mathrm{C}\left(1\right.$ cycle), followed by $30 \mathrm{~s}$ at $98^{\circ} \mathrm{C}, 30 \mathrm{~s}$ at $55^{\circ} \mathrm{C}$, and $75 \mathrm{~s}$ at $68^{\circ} \mathrm{C}(30$ cycles $)$, and a final extension at $68^{\circ} \mathrm{C}$ for $8 \mathrm{~min}$. Finally, one pair of gene-specific primers for full-length $I_{s} F e S O D$ (S1: 5'-GGGATCCATGGCGACAGCGT-3'; S2: 5'-CGGAATTCTTAGAATCCTTTGGG-3') was designed, based on the sequenced 5'- and 3'-fragments, and the full-length FeSOD cDNA was amplified by PCR using these primers. Underlined letters mean enzyme cleavage site.

\section{Bioinformatic analysis}

Homologous sequences were identified by searching the GenBank database using BLAST. Phylogenetic tree was constructed using the MEGA4.1 and ClustalX multiplesequence alignment program.

Genetics and Molecular Research 15 (4): gmr15047131 


\section{Expression and purification of recombinant $\mathrm{FeSOD}$}

The coding region of the FeSOD gene was amplified by PCR. The amplified product was purified, digested with $B a m \mathrm{HI}$ and EcoRI, and cloned into the pET32a vector, predigested with the same restriction enzymes. The resulting plasmid was transformed into Escherichia coli BL21 cells and positive clones were selected. Expression of the recombinant protein was induced by adding $1 \mathrm{mM}$ isopropyl $\beta$-D-thiogalactopyranoside (IPTG) to $E$. coli culture at $37^{\circ} \mathrm{C}$ for $2.5 \mathrm{~h}$. The cells were collected by centrifugation at $5400 \mathrm{~g}$ for $10 \mathrm{~min}$. The cell pellets were washed in $1 \mathrm{~mL}$ Tris- $\mathrm{HCl}, \mathrm{pH} 7.4$, and resuspended in $30 \mathrm{~mL}$ binding buffer $\left(10 \mathrm{mM} \mathrm{NaH}_{2} \mathrm{PO}_{4}, 10 \mathrm{mM} \mathrm{Na}_{2} \mathrm{HPO}_{4}, 500 \mathrm{mM} \mathrm{NaCl}, 30 \mathrm{mM}\right.$ imidazole, $\mathrm{pH}$ 7.4) and lysed by sonication. The suspension was centrifuged at $9000 \mathrm{~g}$ for $10 \mathrm{~min}$ to clarify the enzyme solution. The recombinant protein was analyzed by $12 \%$ SDS-PAGE. The results showed that the expressed proteins were in an insoluble form. Therefore, the recombinant protein was purified from inclusion bodies.

\section{Western blotting}

Soluble, crude protein samples $(5 \mu \mathrm{g})$ were separated using SDS-PAGE with $12 \%$ separating gels and 5\% collecting gels, according to the standard protocol. Proteins were transferred to a polyvinylidene fluoride (PVDF; Millipore, USA) membrane and the FeSOD protein was detected by polyclonal anti-FeSOD antibodies using the Amersham Enhanced Chemiluminescent (ECL) Plus Western Blotting Detection system (GE Healthcare Co. Ltd., UK) on an X-ray film. The densitometry of bands obtained in the western blots was performed by Tannon Gel Image System (Tannon, Shanghai, China).

\section{RESULTS}

\section{Cloning and characterization of IsFeSOD cDNA}

PCRs were performed using degenerate primers and the products were sequenced and analyzed to select clones. A partial gene sequence of about $744 \mathrm{bp}$ that putatively encoded IsFeSOD was obtained. Blast analysis using the online tool available at NCBI revealed that this sequence was partial and contained conserved regions present in other FeSODs. The full-length gene sequence of $I_{S F e S O D}$ was about $1705 \mathrm{bp}$ and was finally obtained using RACE (Figure 1). A phylogenetic tree of some characterized plant FeSODs and IsFeSOD demonstrated that Ceratopteris thalictroides and Matteuccia struthiopteris have the closest gene homology with I. sinensis (Figure 2).

\section{Multiple-sequence alignment of IsFeSOD genes and amino acid sequences of other plants}

BLASTx of the superoxide dismutase gene encoding FeSOD amino acid sequence in I. sinensis and other plants was conducted for homology analysis. The results showed that homology of IsFeSOD with those from other plants, for example, a gymnosperm, Pinus pinaster (GenBank accession No. AAS47494.1) was 63\%. MEGA4.1 application and the ClustalX BootstraPtest software used in ortho-phase algorithm (neighbor-joining) was employed for

Genetics and Molecular Research 15 (4): gmr15047131 
generating a phylogenetic tree (Figure 2), digital branch representative of BootstraP support for the branch. Figure 2 demonstrates the homologous gene relationships between $I_{S} F e S O D$ and $\mathrm{FeSOD}$ of modern ferns, $C$. thalictroides and M. struthiopteris, and mosses with a certain genetic distance.

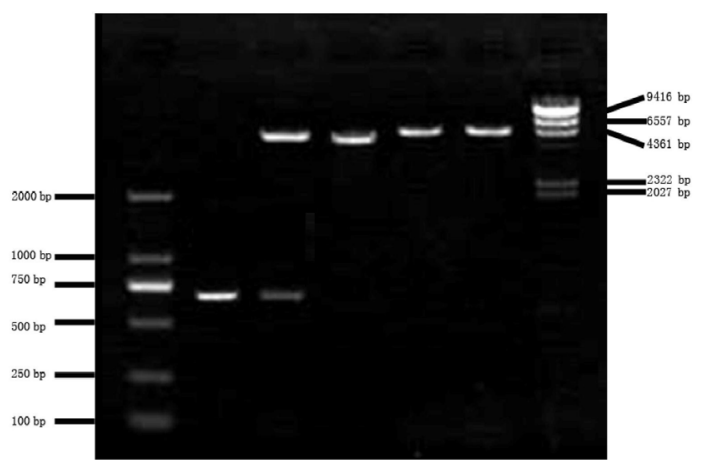

Figure 1. Agarose gel electrophoresis of vector constructs. Lane 1: DL2000 DNA marker, lane 2: PCR product of FeSOD, lane 3: pET32a-FeSOD digested by BamHI/EcoRI, lane 4: pET32a digested by BamHI/EcoRI, lane 5: pET32a-FeSOD digested by BamHI, lane 6: pET32a-FeSOD digested by EcoRI, lane 7: $\lambda$ HindIII DNA marker.

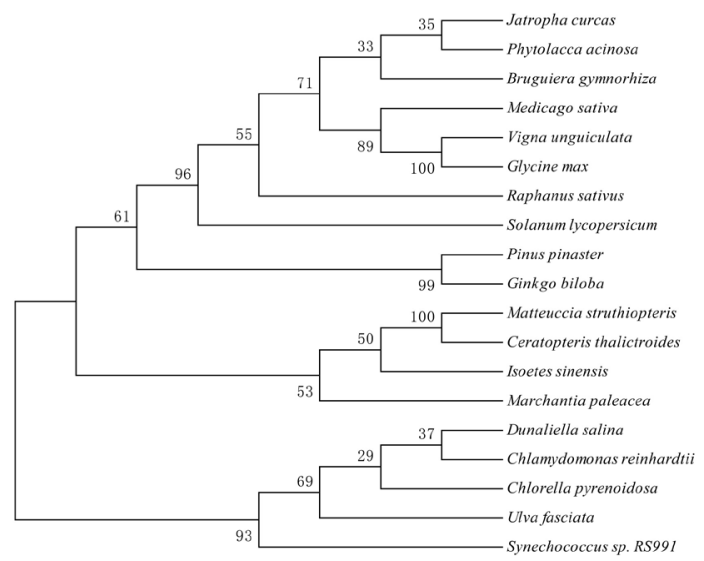

Figure 2. Phylogenetic tree of some characterized plant iron superoxide dismutase synthases and IsFeSOD. Jatropha curcas (NP_001295626), Phytolacca acinosa (AEP14527), Bruguiera gymnorhiza (ADC95630), Medicago sativa (AAL32441), Vigna unguiculata (AAF28773), Glycine max (NP_001238486), Raphanus sativus (AAC15842), Solanum lycopersicum (NP_001233789), Pinus pinaster (AAS47494), Ginkgo biloba (ACL81495), Matteuccia struthiopteris (BAD13298), Ceratopteris thalictroides (ADR01298), Isöetes sinensis (KP036622), Marchantia paleacea (BAC66948), Dunaliella salina (AAX92665), Chlamydomonas reinhardtii (XP_001690591), Ulva fasciata (ABR23159), and Synechococcus sp RS9916 (WP_007098523).

\section{Expression and characterization of recombinant enzyme}

The gene encoding FeSOD harbored an open reading frame of 744 bp encoding 247 amino acids (Appendix 1 and 2). The estimated molecular weight of the protein was $43 \mathrm{kDa}$ (Figure 3). The deduced amino acid sequence of IsFeSOD was compared with the homologous enzymes from $P$. pinaster (PpFeSOD). IsFeSOD showed 63\% identity with PpFeSOD. 


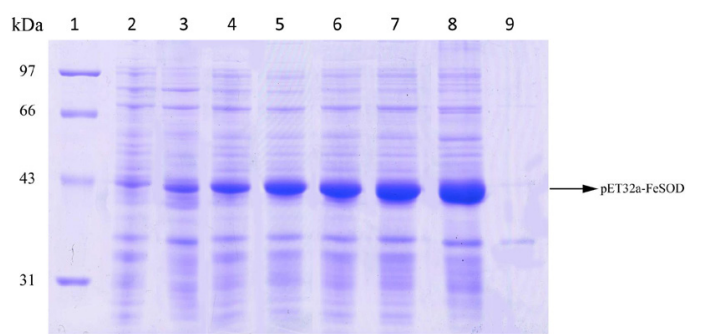

Figure 3. Expression of pET32a-FeSOD in Escherichia coli. Lane 1: protein molecular weight standard; lane 2: total protein without induction; lanes 3-7: protein of E. coli induced by IPTG for $0.5,1,2,4$, and $6 \mathrm{~h}$, respectively; lanes 8 and 9: insoluble and soluble protein in the sample induced for $6 \mathrm{~h}$.

We further aligned complete $\mathrm{FeSOD}$ mRNA sequences from 8 species (Chlamydomonas reinhardtii, Marchantia polymorpha, Barbula unguiculata, I. sinensis, C. thalictroides, $P$. pinaster, Oryza sativa, Arabidopsis thaliana). We observed that FeSOD mRNA sequences were highly homologous to several sequences in the region from 100 to $750 \mathrm{bp}$. Amino acid sequence alignment among these 8 species displayed five highly conserved domains in the FeSOD proteins: FNNA, FGSGW, WEHAYY, WNHHFF, and HWGKH (Figure 4).

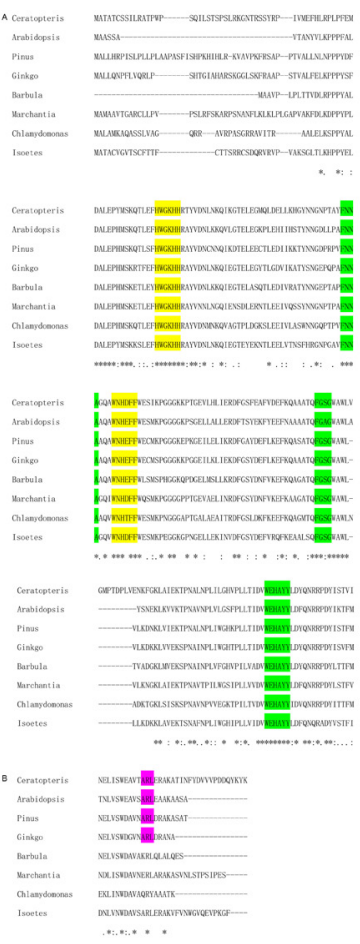

Figure 4. Comparison among amino acid sequences encoded by FeSOD genes of 8 plants. The identical residues among these FeSODs are marked with asterisks. Ceratopteris thalictroides (ADR01298), Arabidopsis thaliana (AAA32791), Pinus pinaster (AAS47494), Ginkgo biloba (ACL81495), Barbula unguiculata (BAC66946), Marchantia paleacea (BAC66948), Chlamydomonas reinhardtii (XP 001690591), and Isöetes sinensis. The first three domains are the most conserved, and the last two just in some species. The conserved ARL (or SRL, pink) sequence is not present in the prokaryotic FeSOD proteins, suggesting that it is not obligatory for the enzyme function.

Genetics and Molecular Research 15 (4): gmr15047131 
In addition, FeSOD sequences of $C$. thalictroides, $P$. pinaster, and A. thaliana encoded for a unique tripeptide ARL close to the carboxy terminus of the enzyme. However, this tripeptide was not found in the FeSOD of I. sinensis. ARL is the location signal of peroxisomes in cells. Although, this sequence directs other proteins to peroxisomes, it is yet to be determined whether this is a functional sequence or not. The conserved ARL (or SRL) sequence is not present in the prokaryotic FeSOD proteins, suggesting that it is not obligatory for the enzyme function. Experimental studies demonstrated that various types of SOD may exert their respective antioxidative functions. For example, MnSOD provides effective protection to DNA, whereas FeSOD was primarily shown to protect the soluble proteins, which were most sensitive to oxidation.

\section{Demonstration of Fe-SOD}

Antibodies specific for FeSOD (Agrisera, Sweden) and FeSOD from I. sinensis were used to demonstrate that the recombinant protein was in fact FeSOD. Western blotting results demonstrated that hybridization signals of recombinant proteins and FeSOD from $I$. sinensis were located at the same position. This proved that the FeSOD gene in I. sinensis was expressed at detectable levels and thus the recombinant protein was FeSOD (Figure 5).

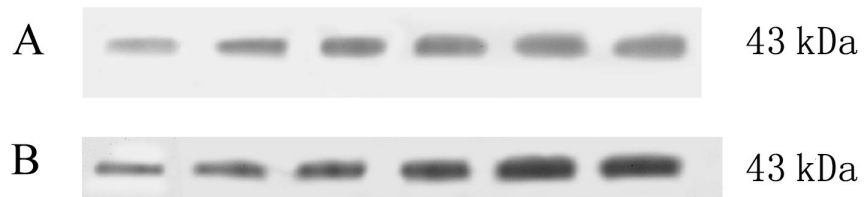

Figure 5. Western blotting to detect FeSOD expression levels of recombinant pET32a-FeSOD with an FeSODspecific antibody, using the Escherichia coli protein induced by IPTG for 0, 0.5, 1, 2, 4, and $6 \mathrm{~h}$.

\section{DISCUSSION}

Absence of FeSOD in animals has led to a proposal that the FeSOD gene originated in the plastids and moved to the nuclear genome during evolution. Support for this theory comes from the existence of several conserved regions that are present in plant and cyanobacterial FeSOD sequences (Kliebenstein et al., 1998), but are absent in nonphotosynthetic bacteria (Bowler et al., 1992). In the present study, complete FeSOD mRNA sequences from 8 species (C. reinhardtii, M. polymorpha, B. unguiculata, I. sinensis, $C$. thalictroides, $P$. pinaster, $O$. sativa, A. thaliana) were aligned. We observed that FeSOD mRNA sequences were highly homologous with several DNA sequences in the region from 100 to $750 \mathrm{bp}$. Amino acid sequence alignment among these 8 species displayed five highly conserved domains in the FeSOD proteins: FNNA, FGSGW, WEHAYY, WNHHFF, and HWGKH. In addition, the Fe-SOD sequences of $C$. thalictroides, $P$. pinaster, and $A$. thaliana encoded a unique tripeptide ARL, which was close to the carboxy terminus of the enzyme. However, the unique tripeptide ARL was not found in I. sinensis. ARL is a signal for peroxisomal localization in cells. Although, this sequence has been shown to direct the proteins to peroxisomes in other proteins, whether this is a functional sequence or not, is still to be determined. The conserved ARL (or SRL) sequence is not present in the prokaryotic FeSOD proteins, showing that it is not obligatory for enzyme function (Van Camp et al., 1990, 1994). Experimental studies

Genetics and Molecular Research 15 (4): gmr15047131 
have shown that different types of SOD could exert their respective antioxidant functions. For example, MnSOD provides effective protection to DNA. FeSOD was primarily shown to protect the soluble proteins, which are most sensitive to oxidation.

Previously, researchers believed that the existence of FeSOD activity in Ginkgoaceae, Nymphaceae, and Cruciferaceae of the plant kingdom was an accidental phenomenon (Salin and Bridges, 1981). Recently, FeSOD genes from three plants, Nicotiana, Arabidopsis (Van Camp et al., 1990), and Glycine max (Crowell and Amasino, 1991), which lack the phylogenetic relationship, were isolated. A large body of research suggests that $\mathrm{Cu} / \mathrm{ZnSOD}$ and MnSOD have priority in higher plants in which FeSOD is absent. Some vascular plants that express FeSOD may have the enzyme protein modified, so as to regain FeSOD activity. In fact, FeSOD and MnSOD are very similar; each subunit in both enzymes contains only one metal ion. MnSOD is mainly in mitochondria from the FeSOD sequence of some biochemical indicators leading to speculate that this enzyme is present in the chloroplast. MnSOD and FeSOD have similar sequences and domain structure. MnSOD exists in clover mitochondria, tobacco chloroplasts, and transgenic plants that are resistant to drought and ozone stress (Van Camp et al., 1996). However, when the plants that excessively express the chloroplast FeSOD and chloroplast MnSOD were treated with paraquat $\left(\mathrm{C}_{12} \mathrm{H}_{14} \mathrm{~N}_{2}\right)$, simultaneously, the former displayed stronger resistance to oxidation than the latter. This difference (Van Camp et al., 1994) may result from the difference in their subcellular localization. Moreover, research on E. coli K-12 suggested that the antioxidant functions of FeSOD and MnSOD are different. MnSOD primarily prevents oxygen free radicals from affecting DNA damage, whereas the main function of FeSOD is the protection of soluble protein that is sensitive to oxidation.

\section{Conflicts of interest}

The authors declare no conflict of interest.

\section{REFERENCES}

Alscher RG, Erturk N and Heath LS (2002). Role of superoxide dismutases (SODs) in controlling oxidative stress in plants. J. Exp. Bot. 53: 1331-1341. http://dx.doi.org/10.1093/jexbot/53.372.1331

Bowler C, Montagu MV and Inze D (1992). Superoxide dismutase and stress tolerance. Annu. Rev. Plant Biol. 43: 83-116. http://dx.doi.org/10.1146/annurev.pp.43.060192.000503

Bowler C, Van Camp W, Van Montagu M and Inzé D (1994). Superoxide dismutase in plants. Crit. Rev. Plant Sci. 13: 199-218. http://dx.doi.org/10.1080/713608062

Chen JM, Liu X, Wang JY, Robert GW, et al. (2005). Genetic variation within the endangered quillwort Isöetes hypsophila (Isoetaceae) in China as evidenced by ISSR analysis. Aquat. Bot. 82: 89-98. http://dx.doi.org/10.1016/j. aquabot.2005.02.007

Ching R (1978). The Chinese fern families and genera: Systematic arrangement and historical origin (Cont.). Acta Phytotax. Sin. 16: 16-37.

Crowell DN and Amasino RM (1991). Induction of specific mRNAs in cultured soybean cells during cytokinin or auxin starvation. Plant Physiol. 95: 711-715. http://dx.doi.org/10.1104/pp.95.3.711

$\mathrm{Fu}$ L (1989). The rare and endangered plants in China. Shanghai Education Press, Shanghai.

Geret F, Manduzio H, Company R, Leboulenger F, et al. (2004). Molecular cloning of superoxide dismutase (Cu/Zn-SOD) from aquatic molluscs. Mar. Environ. Res. 58: 619-623. http://dx.doi.org/10.1016/j.marenvres.2004.03.052

Hoot SB and Taylor WC (2001). The utility of nuclear ITS, a LEAFY homolog intron, and chloroplast atpB-rbcL spacer region data in phylogenetic analyses and species delimitation in Isoëtes. Am. Fern J. 91: 166-177. http://dx.doi. org/10.1640/0002-8444(2001)091[0166:TUONIA]2.0.CO;2

Kliebenstein DJ, Monde RA and Last RL (1998). Superoxide dismutase in Arabidopsis: an eclectic enzyme family with disparate regulation and protein localization. Plant Physiol. 118: 637-650. http://dx.doi.org/10.1104/pp.118.2.637

Genetics and Molecular Research 15 (4): gmr15047131 
Liu HM, Wang L, Zhang XC and Zeng H (2008). Advances in the studies of lycophytes and monilophytes with reference to systematic arrangement of families distributed in China. J. Syst. Evol. 46: 808-829.

Manduzio H, Monsinjon T, Galap C, Leboulenger F, et al. (2004). Seasonal variations in antioxidant defences in blue mussels Mytilus edulis collected from a polluted area: major contributions in gills of an inducible isoform of $\mathrm{Cu} /$ Zn-superoxide dismutase and of glutathione S-transferase. Aquat. Toxicol. 70: 83-93. http://dx.doi.org/10.1016/j. aquatox.2004.07.003

Polle A (2001). Dissecting the superoxide dismutase-ascorbate-glutathione-pathway in chloroplasts by metabolic modeling. Computer simulations as a step towards flux analysis. Plant Physiol. 126: 445-462. http://dx.doi. org/10.1104/pp.126.1.445

Salin ML and Bridges SM (1981). Absence of the iron-containing superoxide dismutase in mitochondria from mustard (Brassica campestris). Biochem. J. 195: 229-233. http://dx.doi.org/10.1042/bj1950229

Scandalios JG (1997). Molecular genetics of superoxide dismutases in plants. Cold Spring Harbor Monograph Archive 34: 527-568.

Van Camp W, Bowler C, Villarroel R, Tsang EW, et al. (1990). Characterization of iron superoxide dismutase cDNAs from plants obtained by genetic complementation in Escherichia coli. Proc. Natl. Acad. Sci. USA 87: 9903-9907. http:// dx.doi.org/10.1073/pnas.87.24.9903

Van Camp W, Willekens H, Bowler C, Van Montagu M, et al. (1994). Elevated levels of superoxide dismutase protect transgenic plants against ozone damage. Nat. Biotechnol. 12: 165-168. http://dx.doi.org/10.1038/nbt0294-165

Van Camp W, Capiau K, Van Montagu M, Inzé D, et al. (1996). Enhancement of oxidative stress tolerance in transgenic tobacco plants overproducing Fe-superoxide dismutase in chloroplasts. Plant Physiol. 112: 1703-1714. http://dx.doi. org $/ 10.1104 / \mathrm{pp} .112 .4 .1703$

Yu YF (1999). A milestone of wild plant conservation in China. Plants 5: 3-11.

Zhang A (1997). Resource and conservation of endangered plants in Kunming. Forest Sci. Technol. 4: 32-33.

\section{Appendix}

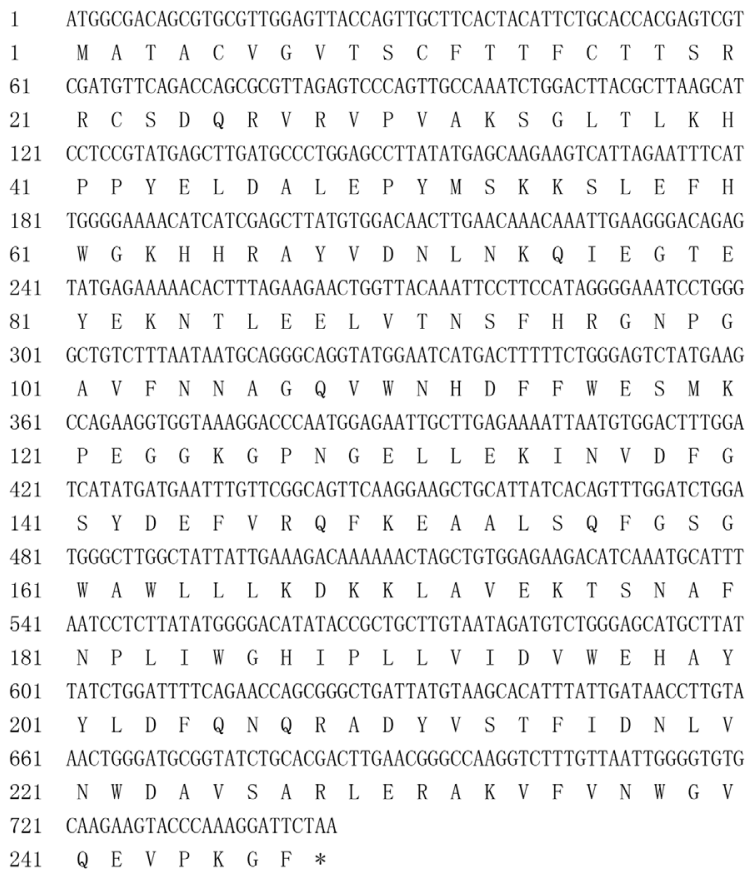

Appendix 1. Nucleotide sequence of ISFeSOD and its putative amino acid sequence Translation of 1-744 universal code total amino acids: 247, MW =28,223 max ORF starts at AA position 1 (might be the DNA position 1) for 247 aa (741 bases), MW = 28,223.

Genetics and Molecular Research 15 (4): gmr15047131 


\begin{abstract}
1 TCtAAtACGA CTCACTATAg GgCAAgAagg tgGtAAAgGA CCCACAgCCC 51 CACGCTTCAA AGAAAGAAAG AATCAGGATT TTGGGTTTAA GCGGATATGG 101 CGACAGCGTG CGTTGGAGTT ACCAGTTGCT TCACTACATT CTGCACCACG 151 AGTCGTCGAT GTTCAGACCA GCGCGTTAGA GTCCCAGTTG CCAAATCTGG 201 ACTTACGCTT AAGCATCCTC CGTATGAGCT TGATGCCCTG GAGCCTTATA 251 TGAGCAAGAA GTCATTAGAA TTTCATTGGg GAAAACATCA TCGAGCTTAT 301 GTGGACAACT TGAACAAACA AATTGAAgGg ACAGAGTATG AGAAAAACAC 351 tTtAgAagAa CTGGtTACAA ATtCCtTCCA tAgGgGAAAT CCTGGgGCTG 401 TCTTTAATAA TGCAGGgCAg GTATGgAATC ATGACTTTTT CTGGGAGTCT 451 ATGAAGCCAG AAGGTGGTAA AGGACCCAAT GGAGAATTGC TTGAGAAAAT

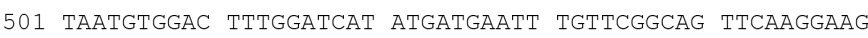
551 CTGCATTATC ACAgtTTGgA TCTGgAtggG CTTGgCTATT ATtgAAAgAC 601 AAAAAACTAG CTGTGGAGAA GACATCAAAT GCATTTAATC CTCTTATATG 651 GgGACATATA CCGCTGCTTG TAATAgAtgt CTGGgAgCAT GCTTATTATC 701 TGgAtTTTCA GAACCAgCGg GCtgAtTATg TAAgCACATT TAtTGATAAC 751 CTTGTAAACT GgGATGCGgt ATCTGCACGA CTTGAACGgG CCAAgGTCTT

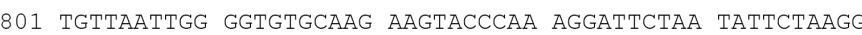
851 AATGTTACCA TACAAAAACA GCCTTTGCAA ATCAGGACCT GGTTGGGGGG

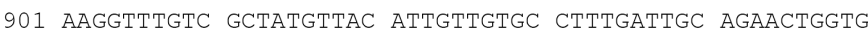
951 GAAGAAACAG GGAAACTGTT TGTGCTCAAT TGGTTGTTGA TCAATTCCAA 1001 GTTTTGCTAT CAGCCAGTGT TCAACACTGG GCTGGACAAC TTGCACCGA 1051 CATtACATtA AAATAgTGgG TTCTTCtAAg AtCTTtCCCC AGAAAgGGA 1101 ATGCGTAATA CCCTGAAATg GAAgAAgAgA ACTTTTGAgT CAATTGTCT 1151 GAAAACTTTT GTGGGCATGC TTTTGTGCAC GTGGGGTGTG CATTGTGAA 1201 GTAGGGAAAA TCTTTATTTA TTGGGATACT GTGAATGACG GAGGAGTTG. 1251 CAAACCTGTT ACGCATTTCT TTTGCTCTAC TAGGAGGACG TGGGCAGGC 1301 tAAATGACAg ATTTATAAAg AAAgtAttAC CCATGGGAAT AGATACAAA 1351 TTGGCAGTGC AGTAATTTCC AAGGGCATCT TGGAGGAAAA AAACAAATG 1401 AgCCTAATGg AgCTTTGgAA AAACAAtATg TGACATGCAT TTAgCAAAA. 1451 AAAAAAAAAA AAAAAAAAA
\end{abstract}

Appendix 2. Full sequence of the IsFeSOD gene.

Genetics and Molecular Research 15 (4): gmr15047131 